\title{
The Co-occurrence of Depressive Symptoms and Cognitive Impairment in a French Community: Are There Gender Differences?*
}

\author{
Rebecca Fuhrer ${ }^{1}$, Toni C. Antonucci ${ }^{2}$, and Jean-François Dartigues ${ }^{3}$ \\ ${ }^{1}$ Research Scientist, Institut National de la Santé et de la Recherche Médicale, (INSERM) U.360, \\ Unité de Recherches Epidémiologiques en Neurologie et Psychopathologie, Villejuif, France \\ ${ }^{2}$ Program Directeur Institute for Social Research, University of Michigan, Ann Arbor, Michigan, USA \\ ${ }^{3}$ Associate Professor, Département d'Informatique Médicale, University of Bordeaux II et INSERM U.330
}

Received July 7, 1992

\begin{abstract}
Summary. The cross-sectional data are reported for cooccurrence of depressive symptomatology and cognitive impairment from the first wave of a longitudinal study of normal and pathological aging in a representative sample of 2792 older adults $(\geq 65)$ residing in the Aquitaine Region (Bordeaux) of Southwest France. The prevalence rate for co-occurrence was $4.2 \%$ for men and $6.2 \%$ for women. Co-occurrence was associated with age, no or little education, functional impairment and dissatisfaction with social support for both men and women, though men were at higher risk than women for the latter two factors, and women were at higher risk than men for no or little education. Women over the age of 85 years were at increased risk whereas men were not, and marital status was associated with co-occurrence for men but had no effect for women. These findings indicate that the risk of co-occurrence differs for men and women, and that, with the exception of social support, the correlates we examined play different roles according to gender.
\end{abstract}

Key words: Depressive symptoms - Cognitive impairment - Co-occurrence - Epidemiology - Gender

The co-morbidity of depression and dementia has been studied in clinical samples, and the concept of pseudodementia has been explored from many perspectives, including diagnostic classification and therapeutic approaches (Folstein and McHugh 1978; Reifler et al. 1982; Reifler 1986; Griffiths et al. 1987). Epidemiological knowledge from clinical studies is scarce concerning the correlates of the co-occurrence of depression and dementia or of pseudo-dementia. Equally little is known from community based samples about depressive symp-

\footnotetext{
* Presented in part at the VI European Symposium on "Psychiatric Epidemiology and Social Psychiatry" of the Association of European Psychiatrists, Zurich, April 1992

Correspondence to: Rebecca Fuhrer
}

toms and cognitive impairment and their relationships to depression and dementia. Henderson (1990) stressed the importance of exploring the co-occurrence of depressive symptoms and cognitive impairment in community samples, in order to gain an unbiased understanding of these psychopathological processes.

Although depressive symptoms in the under 65 age groups are consistently more prevalent among women, gender differences for older adults $(\geq 65)$ are less consistent. Epidemiological studies of elderly community samples have often reported prevalence rates of clinical depression that are lower than those found for younger adults (Gurland 1976; Klerman et al. 1985; Weissman et al. 1985; Regier et al. 1988; Blazer 1989). When depressive symptoms rather than clinical depression was used to define a case of affective disorder, some authors reported that depressive symptomatology was more frequent among the elderly (Zung 1967; Blazer and Houpt 1979) while other authors found no differences (Blazer et al. 1987), and still others reported lower prevalence rates than those found among younger adults (Comstock and Helsing 1976; Eaton and Kessler 1981). In studies which have focused upon the elderly population, there are no reported increases of the diagnosis of clinical depression with age, but there are reports of increasing depressive symptomatology. Among persons 65 years of age or older, depressive symptoms have been found to increase only for men (Berkman et al. 1986), only for women (Kennedy et al. 1989), and for both men and women, though not significantly (Lindesay et al. 1989).

Gender, age and education have been reported to be independent correlates of cognitive impairment, although the effects of each have varied in magnitude depending upon the specific study. In the Boston area EPESE (Established Populations of Epidemiological Studies of the Elderly) survey of 3,682 elderly ( $\geq 65$ ), cognitive performance was inversely related to age (Scherr et al. 1988). In addition, they found that fewer years of formal education, increasing levels of disability as measured by the Katz' Activities of Daily Living Index (ADL) (Katz et 
a1. 1970), and less prestigious occupations, were independently related to lower performance on the tests of cognition. Holzer et al. (1984), Fillenbaum et al. (1988), Gagnon et al. (1990) have reported similar findings. According to Fillenbaum (1988), gender had a minor, though statistically significant, contribution to the Mini Mental State (MMS) (Folstein et al. 1975) score after adjusting for age, education and minority status. Once functional autonomy was included in the model, gender was marginally significant. Gagnon et al. (1990) found that among persons not identified as demented by the DSM-III criteria, women were more likely to score below the MMS threshold, even after adjusting for age, education and depressive symptomatology.

Co-occurrence of depressive symptoms and cognitive impairment appears to be more frequent than would be expected by chance alone. In a community survey of 274 elderly (aged 70 years or more) community residents in Tazmania, Kay et al. (1985) found a significant association between depressive symptoms and cognitive impairment, but no association among clinical cases. Lindesay et al. (1989) obtained similar results in their study of an inner-city London sample. Burke et al. (1988) reported an excess of depressive symptoms amongst cognitively impaired subjects, but they used number of symptoms rather than caseness defined by symptomatology. In a survey of an elderly ( 65 years of age and older) urban community sample $(2,137)$ in New York City, Kennedy et al. (1989) found a significant relationship between depressive symptoms and cognitive impairment only among women aged $75-84$ years. The East Boston study referred to above (Scherr et al. 1988) reported poorer cognitive performance among persons with depressive symptoms. Fuhrer, Antonucci and Dartigues (1991) also found that co-occurrence was independently associated with age, education, functional impairment and the lack of satisfaction with social support. In the USUK cross-national project (Gurland et al. 1983), the cooccurrence of symptoms of depression and cognitive impairment were not correlated in New York nor in London, indicative of no association.

This present paper continues previous work of Fuhrer et al. $(1991,1992)$ by examining gender differences for the correlates of co-occurrence. Although gender was not independently related to co-occurrence, in view of the often reported gender effect for depressive symptoms and cognitive impairment, we wanted to examine whether gender had the role of an effect modifier. More specifically, we wanted to determine whether the correlates of co-occurrence were the same for men and women, and whether the magnitude of the effect was comparable by gender. Variables that have been cited as correlates of depression or depressive symptoms or cognitive impairment were examined in both bivariate and multivariate models, in order to determine their genderspecific relationship to co-occurrence.

\section{Method}

The data for this study are from the PAQUID (Personnes Agées QUID) Research Programme, a prospective epidemiological sur- vey of a representative non-institutional sample of persons over the age of 65 in the Bordeaux region of Southwest France. This longitudinal study includes three interviews during the 5 year follow-up period in addition to the index interview. Of a total of 4,050 eligible persons, $2,792(69 \%)$ participated in the first wave of the study. A full description of the study design and objectives has been reported elsewhere (Dartigues et al. 1991). In brief, subjects were randomly selected based on sex and age, from the electoral registers of a stratified (by size) random sample of cities, towns and villages in the Gironde "département". Interviews were carried out in the subject's home by trained neuro-psychologists. On average, the interviews took one and a half hours, and covered demographic items, past and present medical history including an evaluation of the DSM-III criteria for dementia, family history, social environment, and a battery of neuropsychological tests. In addition, each subject responded to the Center for Epidemiological Studies-Depression (CES-D) scale (Radloff 1977) - a measure of depressive symptomatology, the Mini-Mental State Examination (MMS) (Folstein et al. 1975) - a screen for cognitive impairment, an abbreviated adaptation of the Social Networks in Adult Life Questionnaire (Antonucci and Akiyama 1987) and measures of physical and social functioning - the Activities of Daily Living (ADL) (Katz et al. 1970) and the Instrumental Activities of Daily Living (IADL) (Lawton and Brody 1969).

\section{Depressive Symptomatology}

The CES-D was selected as the measure of depressive symptomatology because it has been shown to be appropriate for use with older adults (Berkman et al. 1986; Radloff et al. 1986). It is a 20 item scale that was developed for use in community studies. It is not intended to provide a diagnosis of depression, nor can it differentiate the cause of the depressive symptoms, which may be due to a depressive disorder, another psychiatric disorder, a physical illness, a medication, or a reaction to an event. The 20 items of the CES-D were selected from previously validated depression rating scales. Respondents specify on a four-point scale of frequency/intensity, the extent to which the feeling or symptom has been experienced during the preceding week. The items reflect the 4 underlying subscales - depressed mood, psychomotor retardation, lack of well being (four positively worded and reversed scored items), and interpersonal difficulties.

The higher the total score, the higher the level of depressive symptomatology expressed by the respondent; the possible range of total scores is from 0 to 60 . In most American studies, a score of 16 and above is considered indicative of an elevated level of depressive symptoms. Validation studies of the CES-D in France demonstrated that the psychological constructs measured are the same as in the United States, but that the cut-off of 16 is not appropriate in the French culture. Receiver Operating Characteristic (ROC) analysis (Weinstein and Fineberg 1980) was used to identify a cut-off appropriate in the French population; when CES-D total scores were compared to psychiatric diagnoses and a clinician rating scale for depression, it was recommended that the cut-of be different for males and females, 17 and 23 respectively (Fuhrer and Rouillon 1989).

\section{Cognitive Impaiment}

The MMS was used to screen for cognitive impairment. It provides a summary measure of the full battery of neuropsychological tests that were administered. The thirty items of this instrument evaluate several domains of cognitive functioning. The total score can range between 30 when all items are correctly answered, and 0 when all items are missed. The distribution of scores is highly skewed, though normal, owing to the fact that a testable subject rarely has a score anywhere close to zero. A score below the threshold of 24 is most frequently used as indicative of impaired cognition (Folstein et al. 1975; Anthony et al. 1982), though in the Epidemiologic Catchment Area (ECA) studies, a score between 23 and 18 was indicative of mild to moderate impairment (Regier 
1984) and a score of less than 18 was indicative of severe impairment. For the results reported here, we used the usual MMS cutoff of $<24$ to classify a subject as cognitively impaired.

\section{Co-occurrence}

Although co-occurrence can be studied from a dimensional perspective by looking at the correlation between the scores and how that correlation is affected by other factors (Fuhrer et al. 1992), this paper examines co-occurrence from a categorical perspective, closer to a diagnostic approach. Hence, co-occurrence of depressive symptomatology and cognitive impairment is defined as having both a CES-D score above the threshold and an MMS score below the threshold of 24 .

\section{Education}

Educational attainment was used as an indicator of social class, and also because of its known relationship to the MMS score. A social class index is not used in France, and the socio-professional category is highly correlated with educational attainment because many jobs require specific degrees or certificates of schooling. A composite index was developed that combines the highest level of school attended and the highest degree obtained. This variable has four categories: No schooling or primary school not completed, Primary school diploma, Secondary school without baccalaureate diploma, Baccalaureate diploma or University attendance.

\section{Functional Autonomy}

Functional ability is highly related to both cognitive functioning and depressive symptoms (Gurland et al. 1987; Fillenbaum et al. 1988; Barberger-Gateau et al. 1992). The IADL is an eight-item instrument that assesses the subject's ability to function autonomously in daily living, such as ability to use the telephone, to shop, to prepare meals, to clean, to do laundry, to use transportation. Each item is scored for independence or dependence based on the subject's autonomy in performing each task; only five items are scored for men, whereas eight are scored for women. Most of the study participants $(88.7 \%)$ had fewer than limitations; hence, linear regression analysis was used to reduce the total score to three categories of functional impairment for both men and women: no limitations, 1 limitation, 2 or more limitations.

\section{Social Support}

Questions from the Social Networks in Adult Life Questionnaire were included to assess social relations and social networks, knowing the importance of these variables in the study of the elderly, as well as in the study of depression (Bowling and Farqhar 1991; Oxman et al. 1992). Social networks, a measure of the structure of the network, and social support or function, a measure of the interactive process of emotional, instrumental and informational assistance, are different constructs of the social environment. In the present analyses, we used the assessment of satisfaction with social support, a measure of quality rather than a measure of the structure or the function of social support. Responses that indicated that the subject was fully satisfied with the quality of his or her social support were categorized as "social support-satisfied", and "social support-dissatisfied" if any dissatisfaction was expressed.

\section{Analyses}

The distribution of depressive symptomatology alone, cognitive impairment alone, and co-occurrence of depressive symptomatology and cognitive impairment, are examined for each candidate correlate (SAS 1991). The referent group consists of all subjects who did not have any one of the three definitions of caseness. Polytomous logistic regression was used to assess the relationship of each correlate to the occurrence of each of the disorders and their co-occurrence (Steinberg and Colla: LOGITSystat 1991). Polytomous logistic regression is a logistic regression model having a dependent variable with more than two outcomes (Hosmer and Lemeshow 1989); 3 models were generated from one maximum likelihood estimation procedure where the dependent variable had 4 possible response categories: depressive symptoms alone, cognitive impairment alone, co-occurrence, and the reference group of no pathology. It is essentially similar to estimating several binary logits simultaneously (Begg and Gray 1984). Multivariate polytomous logistic regression was then used on the combined candidate variables in order to adjust for possible confounders. Age, education, functional autonomy and social support were the correlates of interest, and marital status and urban/ rural residence were considered as possible confounders. The odds ratio (OR) for the independent variables is calculated by exponentiating $\left(e^{\beta}\right)$ the estimated beta coefficient from the logistic regression; it is a measure of the increased risk for a disorder or disease given the presence of the explanatory variable compared with its absence. An odds ratio of 1 indicates that the risk of the disorder is not increased in the presence of the explanatory variable. The $95 \%$ Confidence Interval $(95 \% \mathrm{CI})$ is provided to show the precision of the estimated odds ratio; if the value 1 falls within the confidence interval then it is most likely that the explanatory variable is not associated with the disorder/disease.

\section{Results}

Table 1 presents the characteristics of the sample. Of the 2,792 study participants, $60 \%$ were women and men were younger $($ mean age men/women $=74.2 \mathrm{vs} 75.5, t=5.1, P \leq$ $0.0001)$. The age distribution for men and women differed, with considerably more women over the age of 85 $\left(\chi^{2}=30.7,2 d f, P=0.00\right)$. Most of the men were married $(82 \%)$, whereas the majority of women were widowed $(52 \%)$. Women had less educational attainment than men: $37 \%$ of the women had not attended school at all or had not at least acquired a primary school diploma in contrast to $30 \%$ of the men, whereas $7 \%$ had obtained the baccalaureate degree or attended a university or its equivalent, as compared with $15 \%$ of the men.

Nearly $30 \%$ of the participants reported at least 1 functional limitation; this proportion was greater in women than in men, and as might be expected, the proportion of individuals with limitations increases with age $\left(\chi^{2}=51.8,2 d f, P=0.00\right.$ (result not shown, but available from authors)). The gender effect persists after adjusting for age, which may be due in part to the greater number of questions asked of women.

Most of the study participants reported that they were satisfied with the quality of their social support, though women tended to report more satisfaction than men $\left(\chi^{2}=5.2,1 d f, P \leq 0.02\right)$, and increasing age was 
Table 1. Sample characteristics by gender $(n=2,792)$ (PAQUID Study, Gironde, France 1988)

\begin{tabular}{|c|c|c|c|c|c|}
\hline & \multicolumn{2}{|c|}{$\begin{array}{l}\text { Men } \\
(n=1,120)\end{array}$} & \multicolumn{2}{|c|}{$\begin{array}{l}\text { Women } \\
(n=1,672)\end{array}$} & \multirow[t]{2}{*}{ Test } \\
\hline & $N$ & $(\%)$ & $N$ & $(\%)$ & \\
\hline \multicolumn{6}{|l|}{ Age group } \\
\hline $65-74$ years & 619 & $(55.3)$ & 784 & $(46.9)$ & $\chi^{2}=30.6$ \\
\hline $75-84$ years & 417 & $(37.2)$ & 667 & $(39.9)$ & $2 d f$ \\
\hline$\geq 85$ years & 84 & $(7.5)$ & 221 & $(13.2)$ & $P=0.00$ \\
\hline \multicolumn{6}{|l|}{ Education } \\
\hline No school/primary w/o diploma & 318 & $(29.2)$ & 612 & $(37.4)$ & $\chi^{2}=50.7$ \\
\hline Primary with diploma & 401 & $(36.9)$ & 613 & $(37.4)$ & $3 d f$ \\
\hline Secondary w/o bac & 210 & (19.3) & 298 & $(18.2)$ & $P=0.00$ \\
\hline Bac/university & 159 & $(14.6)$ & 115 & $(7.0)$ & \\
\hline \multicolumn{6}{|l|}{ Marital status } \\
\hline Married/co-habitation & 911 & $(81.8)$ & 634 & $(38.1)$ & $\chi^{2}=527.2$ \\
\hline Widowed & 143 & $(12.8)$ & 861 & $(51.7)$ & $3 d f$ \\
\hline Divorced/separated & 22 & $(3.4)$ & 64 & $(3.8)$ & $P=0.00$ \\
\hline Never married & 38 & $(2.0)$ & 106 & $(6.4)$ & \\
\hline \multicolumn{6}{|l|}{ Place of residence } \\
\hline Urban & 807 & $(72.1)$ & 1,256 & $(75.1)$ & $x^{2}=3.27$ \\
\hline Rural & 313 & $(27.9)$ & 416 & $(24.9)$ & $1 d f, P=0.07$ \\
\hline \multicolumn{6}{|l|}{ Functional autonomy (IADL) } \\
\hline No limitations & 866 & $(77.7)$ & 1,082 & $(65.0)$ & $\chi^{2}=51.8$ \\
\hline 1 limitation & 94 & $(8.4)$ & 203 & $(12.2)$ & $2 d f$ \\
\hline$\geq 2$ limitations & 155 & $(13.9)$ & 380 & $(22.8)$ & $P=0.00$ \\
\hline \multicolumn{6}{|l|}{ Social support } \\
\hline Satisfied & 855 & $(78.7)$ & 1,322 & $(82.3)$ & $\chi^{2}=5.23$ \\
\hline Not satisfied & 231 & $(21.3)$ & 285 & $(17.7)$ & $1 d f, P=0.02$ \\
\hline
\end{tabular}

positively correlated with satisfaction for women only $\left(\chi_{\mathrm{MH}}^{2}=3.8,1 d f, P \leq 0.05\right)$.

\section{Depressive Symptoms and Cognitive Functioning: Examined Separately}

Although the focus of this paper is on the co-occurrence of depressive symptoms and cognitive impairment, it is of interest first to examine the results separately for each of these sub-clinical entities. The prevalence rate of depressive symptoms above the threshold was $13.5 \%$ for men and $14.3 \%$ for women; gender was not a risk factor $(\mathrm{OR}=1.1,95 \% \mathrm{CI}: 0.8-1.3)$.

These rates were estimated for depressive symptoms above the threshold, whether they were associated with cognitive impairment or not. However, in view of the objective of this paper, where the correlates of co-occurrence were compared with those for each pathology, it was more appropriate to examine the correlates of depressive symptoms alone, i.e. among subjects who did not also have poor cognitive functioning. And the reciprocal will be presented for those subjects with poor cognitive functioning alone, i.e. without any associated depressive symptomatology.
Table 2 shows the prevalence rates and crude population odds ratios for depressive symptoms alone. The prevalence rate for depressive symptoms alone increased with age $\left(\chi_{M H}^{2}=9.9,1 d f, P \leq 0.002\right)$ for men only. Furthermore, one observes a trend that older $(\geq 75)$ men had a higher proportion of elevated scores than women, but this trend did not attain statistical significance in our sample. Marital status was associated with depressive symptoms, but this was due to the association for men only. Divorced men were at increased risk $(\mathrm{OR}=4.3$, 95\% CI: 1.4-12.9). Educational attainment and place of residence (urban vs rural) had no apparent association with the occurrence of depressive symptoms alone above the threshold. Men with at least one functional limitation were at increased risk for depressive symptoms alone, in contrast to the finding that the risk for women increased with at least 2 limitations, and the magnitude of the risk was lower for women. Lack of satisfaction with social support increased the risk of depressive symptoms alone three fold for both men and women.

Using the MMS as a screen for cognitive impairment, we found that $24 \%$ of the participants obtained a score below the recommended cut-off of 24 . The rates obtained were comparable to the ECA rates in that for the pre- 
Table 2. Prevalence of depressive symptoms alone and risk estimates for selected variables: by gender $(n=2,792)$

\begin{tabular}{|c|c|c|c|c|}
\hline & \multicolumn{2}{|l|}{ Men } & \multicolumn{2}{|c|}{ Women } \\
\hline & $\begin{array}{l}\text { Preva- } \\
\text { lence } \\
(\%)\end{array}$ & $\mathrm{OR}^{\mathrm{a}}(95 \% \mathrm{CI})$ & $\begin{array}{l}\text { Preva- } \\
\text { lence } \\
(\%)\end{array}$ & $\mathrm{OR}^{\mathrm{a}}(95 \% \mathrm{CI})$ \\
\hline Total & 8.6 & & 8.1 & \\
\hline \multicolumn{5}{|l|}{ Age group } \\
\hline $65-74$ years & 7.9 & 1.0 & 10.7 & 1.0 \\
\hline $75-84$ years & 9.3 & $1.4(0.9-2.3)$ & 6.2 & $0.7(0.5-1.0)$ \\
\hline$\geq 85$ years & 10.3 & $2.0(0.9-4.6)$ & 3.6 & $0.6(0.3-1.5)$ \\
\hline \multicolumn{5}{|l|}{ Education } \\
\hline No school/primary w/o diploma & 5.9 & $1.1(0.6-1.9)$ & 5.5 & $1.0(0.6-1.7)$ \\
\hline Primary with diploma & 10.3 & $1.1(0.7-1.8)$ & 9.9 & $1.2(0.8-1.8)$ \\
\hline Secondary w/o bac & $11.1\}$ & \multirow{2}{*}{1.0} & $9.1\}$ & \multirow{2}{*}{1.0} \\
\hline Bac/university & $7.9\}$ & & $9.7 \int$ & \\
\hline \multicolumn{5}{|l|}{ Marital status } \\
\hline Married/co-habitation & 7.9 & 1.0 & 7.5 & 1.0 \\
\hline Widowed & 9.5 & $1.6(0.8-2.9)$ & 8.7 & $1.3(0.9-2.0)$ \\
\hline Divorced/separated & 23.8 & $4.3(1.4-12.9)$ & 7.9 & $1.0(0.4-2.6)$ \\
\hline Never married & 8.6 & $1.2(0.4-4.2)$ & 7.1 & $1.0(0.4-2.2)$ \\
\hline \multicolumn{5}{|l|}{ Place of residence } \\
\hline Urban & 9.0 & 1.0 & 8.7 & 1.0 \\
\hline Rural & 7.5 & $1.0(0.6-1.7)$ & 6.4 & $0.9(0.5-1.4)$ \\
\hline \multicolumn{5}{|l|}{ Functional autonomy (IADL) } \\
\hline No limitations & 6.8 & 1.0 & 8.3 & 1.0 \\
\hline 1 limitation & 14.1 & $3.4(1.7-6.6)$ & 7.5 & $1.1(0.6-1.9)$ \\
\hline$\geq 2$ limitations & 16.4 & $6.1(3.4-11.0)$ & 7.9 & $2.0(1.3-3.2)$ \\
\hline \multicolumn{5}{|l|}{ Social support } \\
\hline Satisfied & 6.3 & 1.0 & 6.1 & 1.0 \\
\hline Not satisfied & 16.4 & $2.9(1.8-4.6)$ & 16.2 & $3.0(2.0-4.5)$ \\
\hline
\end{tabular}

${ }^{\text {a }} \mathrm{OR}=$ crude odds ratio sent community sample, $20.8 \%$ scored in the mildly impaired range, whereas $3.4 \%$ scored in the severely cognitively impaired range. These proportions differed for men and women $\left(\chi^{2}=24.6,2 d f, P \leq 0.0001\right)$. It should be borne in mind that $3 \%$ of the sample satisfied the DSM-III (APA 1980) criteria for the diagnosis of dementia, and 61 persons $(2.2 \%)$ did not respond to or complete the MMS. If we were to define a probable case of dementia as someone who satisfied the DSM-III criteria as assessed by the psychologist, or scored below the MMS threshold $(<18)$ for severe cognitive impairment, or did not complete the MMS, then we found that $7.5 \%$ of the sample met this definition.

The unadjusted prevalence rates for cognitive impairment alone are shown in Table 3. Women had a moderate, but significant, increased risk for cognitive impairment alone $(\mathrm{OR}=1.6,95 \% \mathrm{CI}: 1.3-2.0)$. The prevalence rate for cognitive impairment alone increased substantially with age for both men and women, and decreased with increasing levels of education. Among men, less education appeared to have a consistently higher risk for cognitive impairment alone when compared with the risk for women. Being widowed, residing in a rural area, and limitations on one's autonomy were all associated with an increased risk for cognitive impairment alone. Social support satisfaction was not associated with poor cognitive functioning.

\section{Co-occurrence}

As shown in Table 4, the prevalence of co-occurrence of depressive symptoms and cognitive impairment was $5.5 \%$ for both men and women combined $(4.4 \%$ for men, $6.2 \%$ for women), $8.3 \%$ of the sample have depressive symptoms alone and $18.1 \%$ are cognitively impaired alone. By chance alone, we would have expected $2.1 \%$ of the sample to report both, but, in fact, nearly $5.5 \%$ did so $(\mathrm{OR}=2.5,95 \% \mathrm{CI}: 2.0-3.1)$. This result was comparable for men $(\mathrm{OR}=2.6,95 \% \mathrm{CI}: 1.8-3.8)$ and women $(\mathrm{OR}=2.4,95 \% \mathrm{CI}: 1.8-3.2)$. As previously indicated in Table 2, men and women did not differ for depressive symptoms alone, but as Table 5 shows, women experience more cognitive impairment with depressive 
Table 3. Prevalence of cognitive impairment alone and risk estimates for selected variables: by gender $(n=2,792)$

\begin{tabular}{|c|c|c|c|c|}
\hline & \multicolumn{2}{|l|}{ Men } & \multicolumn{2}{|l|}{ Women } \\
\hline & $\begin{array}{l}\text { Preva- } \\
\text { lence } \\
(\%)\end{array}$ & $\mathrm{OR}^{\mathrm{a}}(95 \% \mathrm{CI})$ & $\begin{array}{l}\text { Preva- } \\
\text { lence } \\
(\%)\end{array}$ & $\mathrm{OR}^{\mathrm{a}}(95 \% \mathrm{CI})$ \\
\hline Total & 14.4 & & 20.7 & \\
\hline \multicolumn{5}{|l|}{ Age group } \\
\hline $65-74$ years & 9.7 & 1.0 & 11.7 & 1.0 \\
\hline $75-84$ years & 18.2 & $2.3(1.8-3.4)$ & 24.0 & $2.5(1.8-3.3)$ \\
\hline$\geq 85$ years & 30.8 & $4.9(2.8-8.8)$ & 45.0 & $7.5(5.1-11.0)$ \\
\hline \multicolumn{5}{|l|}{ Education } \\
\hline No school/primary w/o diploma & 34.7 & $16.7(9.1-30.7)$ & 35.6 & $5.9(4.1-8.7)$ \\
\hline Primary with diploma & 9.5 & $2.8(1.5-5.4)$ & 14.6 & $1.6(1.1-2.4)$ \\
\hline Secondary w/o bac & $3.9\}$ & 10 & $11.1\}$ & 10 \\
\hline Bac/university & $3.3 \int$ & 1.0 & $7.1 \int$ & 1.0 \\
\hline \multicolumn{5}{|l|}{ Marital status } \\
\hline Married/co-habitation & 13.1 & 1.0 & 16.8 & 1.0 \\
\hline Widowed & 20.4 & $2.0(1.2-3.2)$ & 24.1 & $1.6(1.2-2.1)$ \\
\hline Divorced/separated & 19.1 & $2.1(0.7-6.7)$ & 15.9 & $0.9(0.4-1.8)$ \\
\hline Never married & 22.9 & $2.0(0.9-4.6)$ & 20.4 & $1.2(0.7-2.1)$ \\
\hline \multicolumn{5}{|l|}{ Place of residence } \\
\hline Urban & 11.3 & 1.0 & 8.7 & 1.0 \\
\hline Rural & 22.1 & $2.4(1.7-3.4)$ & 28.1 & $1.8(1.4-2.4)$ \\
\hline \multicolumn{5}{|l|}{ Functional autonomy (IADL) } \\
\hline No limitations & 10.1 & 1.0 & 14.4 & 1.0 \\
\hline 1 limitation & 28.3 & $4.6(2.7-7.8)$ & 23.6 & $2.0(1.3-2.9)$ \\
\hline$\geq 2$ limitations & 32.1 & $8.3(5.1-13.3)$ & 38.7 & $5.7(4.2-7.7)$ \\
\hline \multicolumn{5}{|l|}{ Social support } \\
\hline Satisfied & 15.7 & 1.0 & 22.1 & 1.0 \\
\hline Not satisfied & 8.0 & $0.6(0.3-1.0)$ & 12.9 & $0.6(0.4-1.0)$ \\
\hline
\end{tabular}

${ }^{\text {a }} \mathrm{OR}=$ crude odds ratio symptoms. The odds ratio is $1.6(95 \% \mathrm{CI}: 1.1-2.2)$ for co-occurrence; that is, women are almost $60 \%$ more likely to have both problems simultaneously. For both men and women, the risk for co-occurrence increased with older age, with less education, residence in a rural area, lack of functional autonomy, dissatisfaction with social support (Table 5). Widowhood was associated with an increased risk among men only.

\section{Multivariate Results}

Many of the variables examined are correlated with each other and the significance obtained for some of the crude odds ratios may be due to confounding. By the use of multivariate analysis, the confounding effects are controlled for and the independent effects of each correlate is estimated. The results from the polytomous multiple logistic regression analysis are presented in Table 6. For men, the independent effects of divorce/separation, dissatisfaction with social support and diminished functional autonomy persisted in their relation to depressive symptoms alone after adjusting for the other correlates.
For women, dissatisfaction with social support and at least two limitations in functional autonomy, remained significant at the $P=0.05$ level, and there was a significant decrease in the risk for each extra 10 years of age. Among women, after adjustment for the other correlates, widowhood was in fact associated with depressive symptoms alone.

After fitting the multivariate logistic regression, the apparent association based on the crude odds ratio for age and cognitive impairment alone, was marginally significant for men. Age remained significant, though decreased in effect, for women when all possible confounders were controlled for simultaneously. Educational attainment and functional limitations persisted in the strength of association for both men and women, whereas widowhood was no longer associated $(P=0.50)$ with cognitive impairment alone for men, nor for women. Never married men appear to be at increased risk once other factors are included in the model.

All but one of the correlates that were associated with co-occurrence in the unadjusted analyses remained significant in the full adjusted model. In addition, men in 
Table 4. Co-occurrence of depressive symptomatology and cognitive impairment (PAQUID Study, Gironde, France 1988)

\begin{tabular}{|c|c|c|c|c|c|c|}
\hline \multirow[b]{3}{*}{ MMS } & \multicolumn{4}{|c|}{ CES-D } & \multicolumn{2}{|l|}{ Total } \\
\hline & \multicolumn{2}{|c|}{$\begin{array}{l}\text { Above } \\
\text { threshold }\end{array}$} & \multicolumn{2}{|c|}{$\begin{array}{l}\text { Below } \\
\text { threshold }\end{array}$} & \multirow[b]{2}{*}{$N$} & \multirow[b]{2}{*}{$(\%)$} \\
\hline & $N$ & $(\%)$ & $N$ & $(\%)$ & & \\
\hline $\begin{array}{l}\leq 23 \\
\text { (Cognitive impairment) }\end{array}$ & 147 & $(5.5)$ & 474 & $(18.1)$ & 631 & $(23.6)$ \\
\hline $\begin{array}{l}\geq 24 \\
\text { (No cognitive impairment) }\end{array}$ & 222 & $(8.3)$ & 1,821 & $(68.1)$ & 2,043 & $(76.4)$ \\
\hline Total & 369 & $(13.8)$ & 2,305 & $(86.2)$ & 2,674 & $(100)$ \\
\hline
\end{tabular}

Prevalence odds ratio $\quad=2.5(95 \%$ confidence interval $1.98-3.14)$

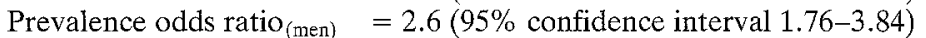

Prevalence odds ratio (women) $=2.4$ (95\% confidence interval $1.81-3.23)$

CES-D: Center for Epidemiological Studies - Depression Scale

(threshold: men $\geq 17$; women $\geq 23$ )

MMS: Mini Mental State Examination (cognitive impairment: <24)

CES-D or MMS incomplete or missing for 118 persons

\begin{tabular}{|c|c|c|c|c|}
\hline & \multicolumn{2}{|l|}{ Men } & \multicolumn{2}{|c|}{ Women } \\
\hline & $\begin{array}{l}\text { Preva- } \\
\text { lence } \\
(\%)\end{array}$ & $\mathrm{OR}^{\mathrm{a}}(95 \% \mathrm{CI})$ & $\begin{array}{l}\text { Preva- } \\
\text { lence } \\
(\%)\end{array}$ & $\mathrm{OR}^{\mathrm{a}}(95 \% \mathrm{CI})$ \\
\hline Total & 4.4 & & 6.2 & \\
\hline \multicolumn{5}{|l|}{ Age group } \\
\hline $65-74$ years & 2.0 & 1.0 & 3.1 & 1.0 \\
\hline $75-84$ years & 7.5 & $4.7(2.3-9.3)$ & 8.0 & $3.1(1.9-5.1)$ \\
\hline$\geq 85$ years & 7.7 & $6.1(2.1-17.0)$ & 12.9 & $8.1(4.4-14.8)$ \\
\hline \multicolumn{5}{|l|}{ Education } \\
\hline No school/primary w/o diploma & 10.9 & $9.7(4.2-22.6)$ & 11.9 & $16.0(6.4-40.3)$ \\
\hline Primary with diploma & 2.1 & $1.1(0.4-3.1)$ & 4.4 & $3.9(1.5-10.3)$ \\
\hline Secondary w/o bac & $2.9\}$ & 10 & $1.7\}$ & 10 \\
\hline Bac/university & $0.7 \int$ & 1.0 & $0.0 \int$ & 1.0 \\
\hline \multicolumn{5}{|l|}{ Marital status } \\
\hline Married/co-habitation & 3.4 & 1.0 & 6.7 & 1.0 \\
\hline Widowed & 11.7 & $4.5(2.3-8.5)$ & 6.5 & $1.1(0.7-1.7)$ \\
\hline Divorced/separated & 4.8 & $2.0(0.3-16.2)$ & 1.6 & $0.2(0.0-1.6)$ \\
\hline Never married & 2.9 & $1.0(0.1-7.4)$ & 4.1 & $0.6(0.2-1.8)$ \\
\hline \multicolumn{5}{|l|}{ Place of residence } \\
\hline Urban & 3.2 & 1.0 & 5.5 & 1.0 \\
\hline Rural & 7.5 & $2.9(1.6-5.1)$ & 8.4 & $1.8(1.2-2.8)$ \\
\hline \multicolumn{5}{|l|}{ Functional autonomy (IADL) } \\
\hline No limitations & 1.4 & 1.0 & 2.3 & 1.0 \\
\hline 1 limitation & 7.6 & $8.8 \quad(3.3-23.5)$ & 6.0 & $3.2(1.5-6.5)$ \\
\hline$\geq 2$ limitations & 21.6 & $39.2(18.6-82.1)$ & 18.7 & $17.6(10.6-29.3)$ \\
\hline \multicolumn{5}{|l|}{ Social support } \\
\hline Satisfied & 3.0 & 1.0 & 4.8 & 1.0 \\
\hline Not satisfied & 8.4 & $3.2(1.7-5.9)$ & 11.4 & $2.7(1.7-4.3)$ \\
\hline
\end{tabular}

Table 5. Prevalence of co-occurrence (depressive symptoms and cognitive impairment) and risk estimates for selected variables: by gender $(n=2,792)$ 
Table 6. Polytomous logistic regression for occurrence and co-occurrence: Adjusted odds ratios and 95\% confidence intervals: OR (95\% CI) (men: $n=1,023$; women: $n=1,519$ )

\begin{tabular}{|c|c|c|c|c|c|c|}
\hline & \multicolumn{2}{|c|}{ CES-D $\geq$ threshold } & \multicolumn{2}{|l|}{ MMS $<24$} & \multicolumn{2}{|l|}{ Co-occurrence } \\
\hline & Men & Women & Men & Women & Men & Women \\
\hline \multicolumn{7}{|l|}{$\begin{array}{l}\text { Age } \\
\text { (referent }=65-74 \text { years })\end{array}$} \\
\hline $75-84$ years & $1.2(0.7-2.0)$ & $0.5(0.3-0.8)$ & $1.5(1.0-2.4)$ & $1.9(1.4-2.6)$ & $2.3(1.0-5.4)$ & $2.0(1.1-3.6)$ \\
\hline$\geq 85$ years & $0.9(0.3-2.4)$ & $0.4(0.1-0.9)$ & $1.9(0.9-4.0)$ & $4.1(2.6-6.7)$ & $1.3(0.4-4.8)$ & $3.7(1.6-8.3)$ \\
\hline \multicolumn{7}{|c|}{$\begin{array}{l}\text { Education } \\
\text { (referent = secondary/bac/univ.) }\end{array}$} \\
\hline No school/primary w/o & $1.1(0.6-2.1)$ & $1.0(0.6-1.7)$ & $14.5(7.6-27.7)$ & $5.4(3.6-8.2)$ & $6.2(2.4-16.1)$ & $14.8(5.6-38.7)$ \\
\hline Primary with diploma & $0.8(0.5-1.4)$ & $1.2(0.8-1.9)$ & $2.3(1.2-4.5)$ & $1.7(1.1-2.5)$ & $0.7(0.2-2.1)$ & $3.6(1.3-9.9)$ \\
\hline \multicolumn{7}{|l|}{$\begin{array}{l}\text { Marital status } \\
\text { (referent = married) }\end{array}$} \\
\hline Widowed & $1.3(0.6-2.6)$ & $1.6(1.0-2.4)$ & $1.2(0.7-2.2)$ & $0.8(0.6-1.2)$ & $2.5(1.1-5.8)$ & $0.5(0.3-0.8)$ \\
\hline Divorced/separated & $4.9(1.5-16.3)$ & $1.1(0.4-2.8)$ & $1.1(0.2-5.7)$ & $0.6(0.3-1.4)$ & $2.1(0.2-24.5)$ & $0.1(0.0-1.1)$ \\
\hline Never married & $1.4(0.4-5.1)$ & $1.0(0.4-2.5)$ & $2.6(1.0-7.3)$ & $0.8(0.4-1.5)$ & $0.7(0.1-7.7)$ & $0.3(0.1-1.0)$ \\
\hline \multicolumn{7}{|l|}{$\begin{array}{l}\text { Place of residence } \\
\text { (referent = urban) }\end{array}$} \\
\hline Rural & $0.9(0.5-1.6)$ & $0.9(0.6-1.5)$ & $1.3(0.9-2.0)$ & $1.3(1.0-1.8)$ & $1.5(0.7-3.0)$ & $1.1(0.7-1.9)$ \\
\hline \multicolumn{7}{|c|}{$\begin{array}{l}\text { Functional impairment } \\
\text { (referent = no limitations) }\end{array}$} \\
\hline 1 limitation & $3.4(1.6-7.0)$ & $1.3(0.7-2.4)$ & $3.5(1.9-6.6)$ & $1.5(1.0-2.3)$ & $8.1 \quad(2.8-23.9)$ & $2.3(1.0-5.1)$ \\
\hline$\geq 2$ limitations & $6.4(3.3-11.9)$ & $2.4(1.4-4.1)$ & $6.9(3.9-12.2)$ & $3.2(2.2-4.6)$ & $27.5(11.7-64.9)$ & $12.7(7.1-23.0)$ \\
\hline \multicolumn{7}{|l|}{$\begin{array}{l}\text { Social support } \\
\text { (referent = satisfied) }\end{array}$} \\
\hline Not satisfied & $3.2(1.9-5.1)$ & $2.7(1.8-4.1)$ & $0.6(0.3-1.1)$ & $0.6(0.4-1.0)$ & $3.5(1.6-7.3)$ & $2.6(1.5-4.4)$ \\
\hline
\end{tabular}

Log likelihood (men): $\quad-690.45$

Log likelihood (women): $-1,244.78$

the 85 year and older age group are no longer at increased risk for co-occurrence. Urban residence was a confounding factor, and its effect was no longer significant after controlling for the other correlates. The magnitude of the effects of age, widowhood for men, and at least 2 functional limitations decreased in the multivariate analysis, whereas the effect of education, 1 functional limitation, social support remained essentially comparable and significant.

The comparison of the coefficients for co-occurrence versus depressive symptoms alone and co-occurrence versus cognitive impairment alone provided an estimate of the increased risk of having both disorders as opposed to each one. Men in the age group 75-84 (OR $=3.2,95 \%$ CI: $1.1-9.6$ ), with the lowest level of education (OR = 10.5, 95\% CI: $2.9-38.1$ ), and at least 2 functional limitations $(\mathrm{OR}=8.7,95 \% \mathrm{CI}: 2.5-30.3)$ were more likely to experience co-occurrence as compared to depressive symptoms alone. Similar findings were obtained for women. Age increased the risk of co-occurrence over depressive symptoms for women $\left(\mathrm{OR}_{75-84}=3.4,95 \%\right.$ CI: $1.5-7.9 ; \mathrm{OR}_{\geq 85}=7.4,95 \%$ CI: $1.9-28.5$ ). Low level of education $(\mathrm{OR}=14.4,95 \% \mathrm{CI}: 4.7-50.0)$ and at least 2 functional limitations ( $O R=5.3,95 \%$ CI: $2.3-12.3$ ) were also associated with an increased risk for co-occurrence among women. For men, only the 75-84 age group had an increased risk, whereas for women the risk increased in magnitude for each 10 year age group.

For men the increased risk for co-occurrence over cognitive impairment alone is for dissatisfaction with social support (OR $=4.8,95 \% \mathrm{CI}: 2.1-11.3$ ) and at least 2 functional limitations $(\mathrm{OR}=3.8,95 \% \mathrm{CI}: 1.5-9.8)$. We obtained the same increased effects for women $\left(\mathrm{OR}_{\text {Dissatis- }}\right.$ faction Social Support $=4.5,95 \% \mathrm{CI}: 2.4-8.3 ; \mathrm{OR}_{\geq 2 \text { Limitations }}=$ $4.4,95 \%$ CI: $2.4-8.3$ ), but in addition, for women, education also was independently associated with an increased risk $\left(\mathrm{OR}_{\text {less than primary school diploma }}=3.4,95 \% \mathrm{CI}: 1.2-9.7\right.$; $\left.\mathrm{OR}_{\text {primary school diploma }}=3.2,95 \% \mathrm{CI}: 1.0-9.5\right)$.

\section{Discussion}

This community based study found that depressive symptoms and cognitive impairment co-occur more frequently than would be expected if they were independent morbid states. The results from this randomly selected sample support the findings from clinical studies. Furthermore, female gender is a determinant of co-occurrence 
when other factors are not controlled. The present cross sectional results also provide evidence for the gender specific and gender similar correlates of co-occurrence. Older age ( $\geq 85$ years of age) and low level of educational attainment have stronger associations with co-occurrence for women than for men. In contrast, functional limitations have a very substantial association for both men and women. Widowhood appears to increase the risk of co-occurrence for men, and is associated with a decrease in risk for women. Low levels of satisfaction with social support has an effect of equal strength on cooccurrence for both men and women. When co-occurrence was compared to depressive symptomatology alone and cognitive impairment alone for each significant variable from the multivariate analyses, the relative increase in risk for the candidate variable did not differ between men and women, except for education.

These results, while naturally influenced by the cutoff levels used, suggest that co-occurrence is an important and relatively frequent event. Our choice of levels for the CES-D was based on previous normative comparative research in France indicating that the score of $\geq 17$ for men and $\geq 23$ for women among the French population is optimal for identifying persons at high risk for depression. The cut-off of $23 / 24$ for the MMS was used to allow the inclusion of both mild and severe cognitive impairment. We believe these decisions were appropriate given the objectives of the study, but recognize that one should be cautious about the generalization of these findings. It is useful to note, however, that additional analyses, not reported here, indicate that neither the exclusion of the DSM-III dementia group nor the use of a more stringent cut-off (20/21) significantly altered the findings reported above.

When depression and cognitive impairment are defined categorically or by diagnosis, the limited number of community based studies precludes any conclusions about consistency of findings. We find $5.5 \%$ of the full sample are both depressed and cognitively impaired. This compares with $2 \%$ reported by Blazer and Williams (1980), $2.9 \%$ reported by Kay et al. (1985), 12\% found by Hasegawa (cited by Henderson 1990), and 4.7\% that we calculated from the tables reported by Kennedy et al. (1989) using severe impairment for case definition. Whereas we obtain a significant association, Kay et al. (1985) found no association between cases of depression and dementia, nor did Lindesay et al. (1989). Although these studies, as ours, have predominantly explored co-occurrence as linear, some attention should be given to the possibility that co-occurrence is non-linear. Fuhrer et al. (1992) reported a moderate, though significant, linear relationship between CESD and MMS scores. Similarly, subgroup analyses of the present data indicate that the proportion of depressive symptoms is equivalent for the mildly impaired (MMS <24) versus severely impaired $(\mathrm{MMS}<18) ; 23.0 \%$ among the mildly impaired and $24.6 \%$ of the severely impaired groups report high levels of depressive symptoms compared with $8.5 \%$ and $11.9 \%$ for those who scored 28 to 30 and 24 to 27 , respectively.

Previous epidemiological studies have not reported on the correlates of co-occurrence. Using data published by Kennedy et al. (1989), we found evidence in their sample for an increased risk of co-occurrence only among women in the 75-84 age group. In the present study, an increased risk was found for all sex and age groups except for men over the age of 85 . Otherwise, the relative odds of co-occurrence were comparable for men and women across the age groups.

Gurland et al. (1987) and Kennedy et al. (1990) have reported on the preeminent contribution of disability to the onset and persistence of depressive symptoms. The prevalence rates presented here illustrate that more depressive symptoms are reported by functionally impaired men than functionally impaired women, despite the fact that most of the men live with someone, which is not the case for the women. Increased disability, as measured by functional limitations, does play an important role for each type for case (depressive symptomatology and cognitive impairment alone, as well as for their co-occurrence) but the impact appears to differ for men and women. This may be due in part to measurement issues. The IADL version employed in this study was scored on 5 items only for men, and 8 items for women, hence men with 1 limitation may be more impaired than women with 1 limitation. This classification decision could have attenuated the effect of the number of limitations for women. The distribution of the IADL total score was highly skewed and the relationship of this score to the dependent variable was non-linear. Hence, it was deemed more appropriate to carry out the analyses on the collapsed score $(0,1,2$ limitations) although the resultant connotation of "disability" may not be the same according to gender.

It is of interest to note the contrast of the effect of widowhood according to gender: it increases the risk of co-occurrence for men but not for women, though it does increase the risk for depressive symptoms alone for women. Nearly $52 \%$ of the women were widowed, compared with $13 \%$ of the men, and most of the men live with someone $(13.7 \%)$ while most of the women do not $(45.5 \%)$, a highly significant difference $\left(\chi^{2}=307.5,1 d f\right.$, $P=0.00)$.

Correlates of co-occurrence are very different from those for depressive symptoms alone, except for satisfaction with social support and functional limitations. On the contrary, the correlates of co-occurrence and cognitive impairment are quite similar. Where results diverge is more in the magnitude of the associations that are found, i.e. an increased risk of co-occurrence for both men and women who have at least 2 functional limitations, and low levels of educational attainment for women only. Also, both men and women who are not satisfied with their support are at increased risk for co-occurrence, but not increased risk for cognitive impairment alone.

Some consideration has also been given to the role of low intelligence or poor education and their influence on the present findings concerning co-occurrence. Certain$1 \mathrm{y}$, it is reasonable to assume that those with low lifetime intelligence or poor educational histories might perform poorly on the MMS and would be inappropriately considered as cases of either cognitive impairment alone 
or co-occurrence and thereby inflate the reported association between education and co-occurrence. We repeated the analyses for each educational stratum to determine whether educational attainment had a confounding effect, and we found that the associations of the other correlates with co-occurrence were consistent across the three educational strata. The present study did not measure life-long low intelligence; it would seem plausible to hypothesize that low intelligence and poor education are correlated and that comparable results would have been obtained had we substituted a measure of life long intelligence.

The association between depressive symptoms and cognitive impairment, and the relationship of co-occurrence to depression and dementia, is yet to be understood or explained. Nevertheless, this question deserves considerable attention in the future. This survey has identified epidemiological correlates of the prevalence of co-occurrence that are gender specific, and it has shown that some factors play roles of different magnitude among men and women. These questions need to be further addressed. It may be that the aetiology of depression and cognitive impairment is different when these conditions occur separately as opposed to when they co-occur. Such distinctions may lead to the discovery of the fundamental and distinctive characteristics of each condition. The longitudinal nature of the study will permit further analyses which will add significantly to the knowledge base on the relevance of co-occurrence to the onset of dementia. It is anticipated that what is known about the factors associated with co-occurrence will contribute to the development of hypotheses that seek to understand the mechanisms that cause the onset of these disorders.

Acknowledgements. The paper was prepared while the first author was on sabbatical at the Institute of Psychiatry, Department of Psychiatry, Section of Epidemiology and General Practice (London). The senior authors thank the Fondation pour la Recherche Médicale for their fellowship award. This research was supported by grants from the Fondation de France, Sandoz Laboratories, French Ministry for Research and Technology, French Social Security (CNAMTS and MSA), l'Institut du Cerveau, AXA Insurance Group, Conseil Régional d'Aquitaine, Conseil Général de la Gironde et de la Dordogne, DRASS Aquitaine, Caisse de Retraite Interentreprises and CAPIMMEC.

\section{References}

Anthony JC, Leresche L, Niaz U, Von Korf MR, Folstein MF (1982) Limits of the 'mini-mental state' as a screening test for dementia and delirium among hospital patients. Psychological Medicine 12:397-408

Antonucci TC, Akiyama H (1987) Social networks in adult life and a preliminary examination of the convoy model. I Gerontology $42: 519-527$

Barberger-Gateau P, Chaslerie A, Dartigues JF, Commenges D, Gagnon M, Salomon R (1992) Health measures correlates in a French elderly community population: The PAQUID Study. J Gerontology $47:$ S $88-95$

Begg C, Gray R (1984) Calculation of polytomous logistic regression parameters using individualized regressions. Biometrika $71: 1-10$

Berkman LF, Berkman CS, Kasl S, Freeman DH, Leo L, Ostfeld AM, Cornoni-Huntley J, Brody JA (1986) Depressive symp- toms in relation to physical health and functioning in the elderly. Amer J Epidemiology 124:372-388

Blazer D (1989) Depression in the elderly. New England J Med $320: 164-166$

Blazer DG, Houpt JL (1979) Perception of poor health in the healthy older adult. J Amer Geriatrics Soc 27:330-334

Blazer D, Hughes DC, George LK (1987) The epidemiology of depression in an elderly community population. The Gerontologist $27: 281-287$

Blazer D, Williams CD (1980) Epidemiology of dysphoria and depression in an elderly population. Amer J Psychiatry 137:439444

Bowling A, Farquhar M (1991) Associations with social networks, social support, health status and psychiatric morbidity in three samples of elderly people. Soc Psychiatry Psychiatric Epidemiology $26: 115-126$

Burke WJ, Rubin EH, Morris JC, Bers L (1988) Symptoms of depression in dementia of the Alzheimer's type. Alzheimer Disease and Associated Disorders 2:356-362

Comstock GW, Helsing KJ (1976) Symptoms of depression of two communities. Psychological Medicine 6:551-563

Dartigues JF, Barberger-Gateau P, Gagnon M, Commenges D, Alperovitch A, Decamps A, Salamon R (1991) PAQUID: Etude épidémiologue du vieillissement normal et pathologique. Revue de Gériatrie 16:5-15

Diagnostic and Statistical Manual of Mental Disorders, 3rd edition (1980) American Psychiatric Association, Washington DC

Eaton WW, Kessler LG (1981) Rates of symptoms of depression in a national sample. Amer J Epidemiology 114:528-538

Fillenbaum GG, Hughes DC, Heyman A, George LK, Blazer DG (1988) Relationship of health and demographic characteristics to Mini-Mental Examination score among community residents. Psychological Medicine 18:719-726

Folstein MF, Folstein SE, McHugh PR (1975) Mini-mental state. J Psychiatric Res 12:189-198

Folstein MF, McHugh PR (1978) Dementia syndrome of depression. In: Katzman, Terry, Bick (eds) Alzheimer's Disease: Senile Dementia and Related Disorders. Raven Press, New York, pp 87-96

Fuhrer R, Rouillon F (1989) La version française de l'échelle CES-D (Center for Epidemiologic Studies-Depression Scale). Description et traduction de l'échelle d'autoévaluation. Psychiatrie et Psychobiologie 4:163-166

Fuhrer R, Antonucci TC, Gagnon M, Dartigues JF, BarbergerGateau P, Alperovitch A (1992) Depressive symptomatology and cognitive functioning: an epidemiological survey in an elderly community sample in France. Psychological Medicine 22:159-172

Fuhrer R, Antonucci TC, Dartigues FJ (1991) Epidemological correlates of co-occurrence of depressive symptoms and cognitive impairment. Presented at Gerontological Society of American Annual Meeting, San Francisco

Gagnon M, Letenneur L, Dartigues JF, Commenges D, Orgogozo JM, Barberger-Gateau P, Alperovitch A, Decamps A, Salomon R (1990) The validity of the Mini-Mental State Examination (MMS) as a screening instrument for cognitive impairment and dementia in a French elderly community residents. Neuroepidemiology 9: 143-150

Griffiths RA, Good WR, Watson NP, O'Donnell HF, Fell P, Shakespeare JM (1987) Depression, dementia and disability in the elderly. Br J Psychiatry 150:482-493

Gurland BJ (1976) The comparative frequency of depression in various adult age groups. J Gerontology 31:283-291

Gurland BJ, Copeland J, Kuriansky J, Kelleher M, Sharpe L, Dean L (1983) The Mind and Mood of Aging. Croom Helm, London

Gurland BJ, Widler DE, Berkman C (1987) Depression and disability in the elderly: reciprocal relations and changes with age. Internal J Geriatric Psychiatry 3:163-179

Henderson AS (1990) Co-occurrence of affective and cognitive symptoms: The epidemiological evidence. Dementia 1:119-123 
Holzer CE, Tischler GL, Leaf PJ, Myers JK (1984) An epidemiologic assessment of cognitive impairment in a community population. In: Greenley JR (ed) Research in Community and Mental Health. AI Press, Greenwich, CT, pp 3-32

Hosmer DW, Lemeshow S (1989) Applied Logistic Regression. Wiley, New York

Katz S, Downs TD, Cash HR, Grotz RC (1970) Progress in development of the index of ADL. The Gerontologist 10:20-30

Kay DWK, Henderson AS, Scott R, Wilson J, Rickwood D, Grayson DA (1985) Dementia and depression among the elderly living in the Hobart community: the effect of the diagnostic criteria on the prevalence rates. Psychological Medicine 15:771788

Kennedy GJ, Kelman HR, Thomas C, Wisniewski W, Metz H, Bijur PE (1989) Hierarchy of characteristics associated with depressive symptoms in an urban elderly sample. Amer J Psychiatry 146:220-225

Kennedy GJ, Kelman HR, Thomas C (1990) The emergence of depressive symptoms in late life: the importance of declining health and increasing disability. J Comm Health 15:93-104

Klerman G, Lavori PW, Rice J, Reich T, Endicott J, Andreasen NC, Keller MB, Hirschfield RMA (1985) Birth-cohort trends in rates of major depressive disorder among relatives of patients with affective disorder. Arch General Psychiatry 42:657666

Lawton MP, Brody EM (1969) Assessment of older people: selfmaintaining and instrumental activities of daily living. The Gerontologist 9:179-186

Lindesay J, Briggs K, Murphy E (1989) The Guy's / Age concern survey: prevalence rates of cognitive impairment, depression and anxiety in an urban elderly community. $\mathrm{Br} \mathrm{J}$ Psychiatry $155: 317-329$

Oxman TE, Berkman L, Kasl S, Freeman DH, Barrett J (1992) Social support and depressive symptoms in the elderly. Amer J Epidemiology 135:356-368

Radloff LS (1977) The CES-D scale: A self-report depression scale for research in the general population. Appl Psychological Measurement 1:385-401
Radloff LS, Teri L (1986) Use of the Center for Epidemiological Studies. In: Brink TL (ed) Depression scale with older adults. Clin Gerontology 6:119-136

Regier DA, Myers JK, Kramer M, Robins LN, Blazer DG, Hough RL, Eaton WW, Locke BZ (1984) The NIMH epidemiologic catchment area (ECA) program: Historical context, major objectives and study population characteritics. Arch Gen Psychiatry $41: 934-941$

Regier DA, Boyd JH, Burke JD, Rae DS, Myers JK, Kramer M, Robins LN, George LK, Karno M, Locke BZ (1988) Onemonth prevalence of mental disorders in the United States: based on five epidemiologic catchment area sites. Arch Gen Psychiatry 45:977-986

Reifler BV (1986) Mixed cognitive affective disturbances in the elderly: A new classification. J Clin Psychiatry 47:354-356

Reifler BV, Larson E, Hanley R (1982) Coexistence of cognitive impairment and depression in geriatric outpatients. Amer $\mathrm{J}$ Psychiatry $139: 623-626$

SAS User's Guides (1985) Basics and Statistics Manuals - Version 5.18 Edition. SAS Institute, Cary, NC

Scherr PA, Albert MS, Funkenstein HH, Cook NR, Hennekens CH, Branch LG, White LR, Taylor JO, Evans DA (1988) Correlates of cognitive function in an elderly community population. Amer J Epidemiology 128:1084-1101

Steinberg D, Colla P (1991) LOGIT: A supplementary module for SYSTAT. SYSTAT Inc, Evanston, IL

Weinstein MC, Fineberg HV (1980) Clinical Decision Analysis. Saunders, Philadelphia

Weissman MM, Myers JK, Tischler GL, Holzer CE, Leaf PJ, Orvaschel H, Brody JA (1985) Psychiatric disorders (DSM-III) and cognitive impairment among the elderly in a U.S. urban community. Acta Psychiatrica Scandinavica $71: 366-379$

Zung WWK (1967) Depression in the normal aged. Psychosomatics $8: 287-292$ 